\title{
ABCD of Child Psychiatry: A Newer Understanding
}

\author{
Shyamanta Das* \\ Department of Psychiatry, Gauhati Medical College Hospital, India
}

Submission: August 14, 2017; Published: September 14, 2017

*Corresponding author: Shyamanta Das, Department of Psychiatry, Gauhati Medical College Hospital, 10, CK Agarwalla Road, Ambari, Uzan Bazar, Guwahati, Assam, India, Email: dr.shyamantadas@gmail.com

Abstract

In light of the high occurrence of mental and behavioral disorders as well as sub-syndromal symptomatology causing burden in the population of children and adolescents, early detection and appropriate management is the need of the hour. But, there are hurdles to overcome, including 'gate keeping' of different stakeholders. Thus, in order to speak a 'common language', a newer classification is discussed along with the feasibility of such a system in a developing region like the North-East India.

Keywords: Mental disorders; Behavioral disorders; Adolescents

\section{Introduction}

Psychiatry is the branch of medical science that deals with disorders of affect, behavior, and cognition (ABC) [1]. What about the mental and behavioral disorders in childhood and adolescence? Is it a myth or a reality? A PubMed search with the keywords "mental disorders", "behavioral disorders", "childhood", and "adolescence" resulted in 14245 items [2].

Not only mental and behavioral disorders in childhood and adolescence are commonplace but these disorders also prove to become a burden in these age groups. What more, there are sub syndromal symptomatology causing suffering in children and adolescents [3]. When we apply adult criteria to diagnose mood disorders in very young children, our findings reveal 'nil' prevalence. But children are crying and they need help. It is now clear that one half of all psychiatric disorders have their first appearance of symptoms during childhood and if we include the adolescence then the figure rises to two-third [4]. These have both preventive and therapeutic implications.
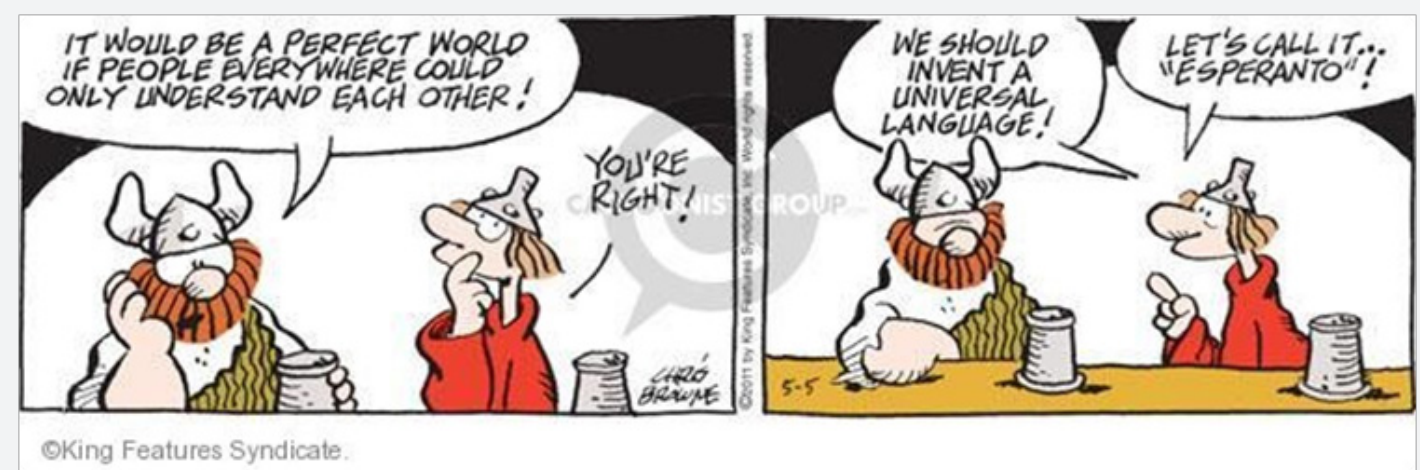

Figure 1: Common language.

Stigma, Self-Sufficiency, Barriers, and "Gatekeepers"!

Stigma and self-sufficiency are important barriers in early detection and appropriate management of psychiatric disorders [5]. This is more so in case of childhood and adolescence psychiatric disorders [6,7]. In addition, this population comes across several "gatekeepers" in the forms of parents, teachers, general physicians, and pediatricians before reaching mental health professionals [3]. Therefore, it is pertinent that we all speak one "common language" understandable to all the stakeholders. Something like this where Hagar the Horrible is in conversation with Lucky Eddie (Figure 1)!

Otherwise, think of a situation where a child coming to a psychiatrist with 'emotional and behavioral problems' and what could be the reaction of the stakeholders when the psychiatrist 
makes a diagnosis of, say 'Acute polymorphic psychotic disorder with symptoms of schizophrenia without associated acute stress' (ICD code F23.10) [8]. Leave aside lay persons like parents and teachers, even our colleagues from other departments will get confused.

\section{New Classification}

A simple and valid way of classifying childhood and adolescent psychiatric disorders is to categorise them into three groups, namely developmental disorders, disruptive disorders, and emotional disorders; it is also observed that within group comorbidity is commonplace compared to that of across groups $[3,9]$.

Our pilot project on the subject was carried out in the Fakhruddin Ali Ahmed Medical College Hospital (FAAMCH), Barpeta [10]. Twenty six children and adolescents attending psychiatry outpatient department were studied. Age range was up to 15 years and of them 16 were boys. Emotional, disruptive, and developmental disorders were found in nine, five, and ten children and adolescents respectively. As far as comorbidty was concerned, the number was same in both within each grouping and across groups.

Similar work was conducted in the Gauhati Medical College Hospital (GMCH), Guwahati among indoor patients. Age range was from 8 to 17 years and 62 were girls. Of the total sample of 94 children and adolescents, majority (48) had emotional disorders. Comorbidity was again equal in both within each grouping and across groups [11].

In the month of October 2015, at the initiative and relentless pursuance of Professor Dipesh Bhagabati, then Head of the Department, a child psychiatry unit was born. This 12-bedded child and adolescent unit started functioning in the Department of Psychiatry, GMCH consisting of three beds for each sex in both age groups of up to 12 and $12+$ to 18 years.

Our recent work was carried out in this child psychiatry unit [12]. Sample was almost equally divided in the two age groups as well as between the sexes. The distribution of emotional, disruptive, and developmental disorders in the younger and older age groups were 4:3:2 and 5:0:1 respectively. The same for boys and girls were $4: 2: 1$ and 4:1:2 respectively. Comorbidity was same within group and across groups.

\section{ICD-11}

"The 11th Revision of the International Classification of Diseases (ICD-11) is due by 2018!"[13]. Therefore, we expect some changes from in vogue tenth revision (ICD-10) [8]. While participating in the Internet-Based Field Study for ICD-11 Mental and Behavioral Disorders as a member of the Global Clinical Practice Network (GCPN), yours truly came across one proposed term in child psychiatry by the World Health Organization's Department of Mental Health and Substance Abuse as "Disruptive Behavior and Dissocial Disorders" [14].

\section{The "fourth estate"!}

Though the new classification proposes three categories, our preliminary experiences show that all childhood and adolescent psychiatric disorders may not fit into the scheme of things [10-12]. In our recent work, [12] “ $56.25 \%$ of children and adolescents had received diagnoses that are not incorporated in the current scheme of things. This category of disorders included schizophrenia, acute and transient psychotic disorders, unspecified nonorganic psychosis, manic episode, bipolar affective disorder, and schizoaffective disorder". In an earlier study of ours, [11] "we found $40.43 \%$ of the sample size to consist of these diagnoses. The possibility of these disorders, i.e. schizophrenia spectrum disorders, affective and nonaffective psychotic disorders presenting in similar fashion in both adulthood and during childhood and adolescence should be considered."

Do the so-called 'major psychoses' need separate identity from that of adulthood? Psychosis is a defining feature in acute and transient psychotic disorder, delusional disorder, schizophrenia, and schizoaffective disorder and an associated feature in mood [affective] disorders, both unipolar and bipolar [15].

This fourth group, we termed 'dysfunctional' disorder. Now we have emotional disorders or affective disorders where primary pathology lies in emotion or affect. We have disruptive disorders or behavioral disorders as disturbance of behavior is the prominent feature here. We also have developmental disorders or cognitive disorders where deficits in cognition stand out. Add to this the dysfunctional disorders, and the $\mathrm{ABC}$ of psychiatry that we talked of in the beginning, i.e. affective, behavioral, and cognitive disorders becomes ABCD in child psychiatry, i.e. affective (or emotional), behavioral (or disruptive), cognitive (or developmental), and dysfunctional disorders.

\section{Hurdles}

Such a diagnostic system is not full-proof in itself. Two obvious hurdles that come to mind are: terminology and reductionism. As far as terminology is concerned, the terms like emotional, disruptive, developmental are commonly used in popular conversations. But, here we are using them for medically diagnosable conditions. There is high probability that the same will be used for 'emotional and behavioral problems' not entitled enough to be called disorders. On the other way around, when medical disorders are called with these names, there is the chance of neglecting the impact such disorders can have and thus ignoring their proper management.

The second hurdle is that such a newer approach to classification may be criticized for being reductionist. We admit that it is a reductionist approach. So, does it mean that we are going backward as far as what contemporary psychiatry is saying? 


\section{"Personalised medicine in psychiatry"}

What are the 'contemporary issues in psychiatry', by the way? Certain developments worth noting in contemporary psychiatry include Matcheri Keshavan and his team's Bipolar and Schizophrenia Network for Intermediate Phenotype, BNIP in short, [16] Thomas Insel and his team's Research Domain Criteria or RDoC initiative [17], Stephen Stahl's deconstructing syndrome into symptoms [18], and Joseph Zohar and his team's Neuroscience-based Nomenclature (NbN) [19]. On one hand there is an attempt for a brain-based diagnostic system [20] and on the other the attempt is to have a mechanism-based classification of treatment instead of categories [21]. We all know the fallacy of calling, say for example escitalopram as antidepressant. Though used in depressive episode, another patient with panic disorder may come and say that you have given him an antidepressant for his anxiety disorder!

So the journey is from phenomenology through Neurocircuitry [22] to biological and molecular psychiatry. A corollary of which we can found in oncology. Our current diagnostic systems of ICD and DSM are comparable to TNM classification, i.e. tumour, node, metastasis. Oncology has moved from TNM classification to Human Epidermal Growth Factor Receptor 1 (HER-1) and 2 (HER-2). Similar is this journey of ours. Treatment needs to be tailor-made according to the need of the patient, or in other words, 'personalized medicine in psychiatry' [23].

\section{Revolutions of psychiatry}

Enlightenment from middle Ages is considered psychiatry's first revolution. Second revolution coincides psychoanalysis. Pharmacotherapy for psychiatric disorders is the third revolution. Subsequent developments in community psychiatry is the fourth revolution when as a result of pharmacotherapy patients moved from institution to de-institution (ignoring or incorporating the phase of trans-institutionilasation) [1].

Currently we are having a common brain biology based approach for both the diagnosis as well as treatment of psychiatric disorder. Does this signify our "entering the fifth revolution of psychiatry" [24]?

\section{"Eyes that guide"}

Axl Rose asks "Where do we go now" in the GNR's legendary number "Sweet child o' mine" [25]. Similarly in the light of contemporary developments in psychiatry, where does this new classification stand? This is for diagnosis only. As far as management is concerned, the 'individualized' or 'personalized' medicine is also what we advocate for: "Eyes that guide" [26].

With the birth of a child, the new parents become apprehensive about how best to take care. How frequently should feeding be given, how many times should the child pass urine and stool, is crying signifies something grave? Advises pour in from various quarters: starting from lay comments in the forms of aunty and grandmother, to professional commentaries of general physician and paeditrician. But with time the parents come to know that their own child her/himself is the best guide. They come to terms that every child is unique in her/his own way and the care needs to be tailor-made accordingly.

Even a diagnosis of say for example, 'schizophrenia' does not carry much information as long as choosing its treatment is concerned. What we need to do, as contemporary developments show, deconstruct the syndrome to its component domains and units up to the symptoms. And then try to locate the malfunctioning neuro-circuits and decide upon the best way to correct them through treatment. Likewise, the same approach is what calls for in childhood and adolescence disorders as well, that we intent to call by these simple names!

\section{Conclusion}

To live in peace without countries and religions is what John Lennon "imagined" [27]. "Where the streets have no name" is Bono of U2's destination [28]. So do we wish for childhood and adolescence psychiatric disorders "where if we cannot live without names then let us at least have few and simple ones": [29] ABCD!

\section{Acknowledgement}

The Meghalaya State Branch of the Indian Psychiatric Society (MEGHIPS) invited the author to speak in their Midterm CME held in Shillong on 29 July 2017 and this article is prepared as part of that presentation.

\section{References}

1. Ahuja NA (2011) Short textbook of psychiatry. ( $7^{\text {th }}$ edn), Jaypee Brothers Medical Publishers, New Delhi, India.

2. NCBI (National Center for Biotechnology Information) US. National Library of Medicine, 8600 Rockville Pike, Bethesda MD, 20894 USA.

3. Scott S (2009) Developmental psychopathology and classification in childhood and adolescence. In: Michael Gelder, (Eds.), New oxford textbook of psychiatry. (2 $2^{\text {nd }}$ Edn). Oxford: Oxford University Press, United Kingdom, pp. 1589-1594.

4. Kessler RC, Berglund P, Demler O, Jin R, Merikangas KR, et al. (2005) Lifetime prevalence and age-of-onset distributions of DSM-IV disorders in the National Comorbidity Survey Replication. Arch Gen Psychiatry 62(6): 593-602.

5. Kumar A, Phookun HR (2016) Barriers in the treatment of psychiatric disorders. Open J Psychiatry Allied Sci 7: 99-102.

6. Das S, Hazarika M (2016) It's different! Stigma and attitude in child psychiatry. Symposium presentation during the $17^{\text {th }}$ Annual National Conference of Indian Association of Private Psychiatry (ANCIAPP 2016) at ITC Sonar, Kolkata, India.

7. Das S, Talukdar S, Bhandari SS, Das B, Nath K, et al. (2016) A different stigma and attitude in child psychiatry [Internet]. Paper presentation during the $22^{\text {nd }}$ World Congress of the World Association of Social Psychiatry (WASP 2016) at The Ashok, New Delhi, India.

8. World Health Organization (1992) The ICD-10 classification of mental and behavioural disorders: clinical descriptions and diagnostic guidelines. World Health Organization, Geneva, Switzerland.

9. Dogra R, Kumar K, Gupta A (2013) Mental health in children: an overview. Dysphrenia 4(2): 113-22. 
10. Das S, Talukdar U, Dey P (2015) Children at dawn: the pattern of childhood psychiatric disorders in a newly opened academic medical centre. Delhi Psychiatry Journal 18(1): 126-132.

11. Das S, Bhagabati D, Mathur P, Kalita A, Sengupta N, et al. (2015) Study of psychiatric disorders in children and adolescents to introduce a newer classification system. Journal of Research in Psychiatry and Behavioral Sciences 1(1): 6-10.

12. Das S, Bora U, Borbora SA, Kalita A, Mathur R, et al. (2017) An observational study towards a newer classification in child psychiatry. Open J Psychiatry Allied Sci 8: 35-39.

13. World Health Organization (2017) The 11th revision of the International Classification of Diseases (ICD-11) is due by 2018.

14. Academy Publisher ICD-11 (2017) Jan 30.

15. American Psychiatric Association (2013) Diagnostic and statistical manual of mental disorders. ( $5^{\text {th }}$ edn.), Arlington, American Psychiatric Association, USA, pp. 991.

16. Keshavan MS, Morris DW, Sweeney JA, Pearlson G, Thaker G, et al. (2011) A dimensional approach to the psychosis spectrum between bipolar disorder and schizophrenia: the Schizo-Bipolar Scale. Schizophr Res 133(1-3): 250-254.

17. Insel TR (2014) The NIMH Research Domain Criteria (RDoC) Project: precision medicine for psychiatry. Am J Psychiatry 171(4): 395-397.

18. Stahl SM (2008) Stahl's essential psychopharmacology: neuroscientific basis and practical applications. ( $3^{\text {rd }}$ Edn.), New York: Cambridge University Press.

19. Zohar J, Kasper S (2016) Neuroscience-based Nomenclature (NbN): a call for action. World J Biol Psychiatry 17(5): 318-320.
20. Das S (2014) Brain-based diagnostic system. In: Book of abstracts-international conference on disease biology and therapeutics. Institute of Advanced Study in Science and Technology, Guwahati, India, p. 22.

21. Talukdar U (2014) Psychopharmacological approach according to mechanism vs. category. In: Book of abstracts--international conference on disease biology and therapeutics. Institute of Advanced Study in Science and Technology, Guwahati, p. 24.

22. Bardhan N (2014) From phenomenology to neurocircuitry. In: Book of abstracts--international conference on disease biology and therapeutics. Institute of Advanced Study in Science and Technology, Guwahati, India, p. 23.

23. Elsevier BV (2017) Personalized medicine in psychiatry [serial online].

24. Das S, Hazarika M, Bardhan N, Talukdar U, Bhagabati D, Bora U (2015) Fifth revolution of psychiatry. Das S, Medhi D, Dutta J, Chakaravarty S (Eds.), Brain understanding of mental illness. Academy Publisher, Guwahati, India, 1-10.

25. Guns N' Roses (1987) Sweet child o' mine. In: Appetite for destruction. Geffen (Ed.), USA.

26. Talukdar S (2016) About the cover: Eyes that guide. Open J Psychiatry Allied Sci 7(1).

27. Lennon J (1971) Imagine. In: Imagine. Apple.

28. U2 (1987) Where the streets have no name. In: The Joshua tree. Island.

29. Das S, Bora U, Borbora SA, Kalita A, Mathur R, et al. (2017) An observational study towards a newer classification in child psychiatry. Open J Psychiatry Allied Sci 8(1): 35-39.

This work is licensed under Creative

Commons Attribution 4.0 Licens

DOI: 10.19080/GJIDD.2017.03.555602
Your next submission with Juniper Publishers will reach you the below assets

- Quality Editorial service

- Swift Peer Review

- Reprints availability

- E-prints Service

- Manuscript Podcast for convenient understanding

- Global attainment for your research

- Manuscript accessibility in different formats ( Pdf, E-pub, Full Text, Audio)

- Unceasing customer service

Track the below URL for one-step submission https://juniperpublishers.com/online-submission.php 